\title{
RECONHECIMENTO DE TERMOS E MARCADORES DE DEFINIÇÃO: UMA ABORDAGEM QUALITATIVA*
}

\author{
Anna Maria Becker Maciel** \\ Karoll Ribeiro e Silva Ferreira ***
}

\begin{abstract}
RESUMO: Este estudo exploratório investiga duas hipóteses: a) se a ocorrência de termos pode ser indicada por um marcador de definição ou por um elemento que assinala uma explicação do significado; b) se tais marcadores configuram-se diferentemente de acordo com a área especializada, os propósitos da comunicação e o contexto situacional em que ocorrem.
\end{abstract}

UNITERMOS: reconhecimento de termos; marcadores de definição; terminologia; terminografia.

ABSTRACT: This exploratory study investigates two hypotheses: a) whether the presence of terms can be indicated by a definition marker or by an element signaling an explanation of meaning, b) whether such markers take up different configurations according to the specialist area, the communicating purposes and the situational context where they occur.

KEYWORDS: term recognition, definition markers, terminology, terminography.

* Texto apresentado como comunicação no $13^{\circ}$ INPLA: Metodologia de Pesquisa em Lingüística Aplicada. LAEL/PUCSP, realizado em São Paulo em maio de 2003.

** Universidade Federal do Rio Grande do Sul.

*** Programa Institucional Bolsa de Iniciação Científica CNPq/UFRGS. 


\section{Introdução}

Esta pesquisa acompanha as tendências da Terminologia contemporânea, que considera o termo um item lexical da língua comum, funcionando como um vetor de conhecimento na comunicação especializada. Nessa perspectiva, a funcionalidade pragmática ativada pelos propósitos da área configura o caráter específico do termo na realização textual (Cabré, 1999; Temmerman, 2001). Este trabalho também encontra suporte nos pressupostos teóricos e na abordagem metodológica da Lingüística de Corpus (Biber, 2002; Stubbs, 1996). Esse suporte se justifica não apenas porque a pesquisa recorre ao computador como instrumento de trabalho, mas principalmente porque se desenvolve em um construto que dá primazia ao desempenho do falante no ambiente autêntico de textos reais e privilegia a probabilidade da recorrência de determinadas características lingüísticas. Nesse direcionamento, foram selecionados textos de uma área de especialidade para, com o auxílio de recursos informatizados, identificar estruturas lingüísticas recorrentes na formulação de definições.

Tais estruturas são os marcadores de definição, objeto deste estudo: sinais que aparecem na superficie textual, sinalizando a ocorrência de unidades lexicais especializadas, ou introduzindo esclarecimentos sobre seu significado. São indícios de natureza lingüística ou simplesmente de natureza gráfica que, aparecendo no texto, guiam o leitor no processo de compreensão.

Para delinear o estado da questão e assim poder mais facilmente posicionar este estudo, mencionamos o trabalho dos principais pesquisadores que encontramos ao realizar a revisão da literatura. Em seguida, ao especificar a metodologia adotada, descrevemos a constituição do corpus, enfatizando a motivação da seleção de textos e da ferramenta computacional utilizada. Então, apresentamos o desenvolvimento das diferentes etapas do processo da análise que levou à configuração dos marcadores coletados. Finalmente, como uma conclusão parcial de um estudo exploratório que será posteriormente desenvolvido, discutimos os resultados alcançados e apontamos para futuras pesquisas. 


\section{Estado da questão}

Muitos autores já investigaram os marcadores da definição em sua forma canônica, isto é, na forma em que aparecem no dicionário. Hathout (1996), por exemplo, examinou as marcas superficiais das definições de Química e Botânica numa extensa obra lexicográfica, o Trésor de la langue française. Finatto (2001) identificou marcadores enunciativos nas definições de dicionários de Química e de Ciência Política. Outros ainda foram além das formulações dos dicionaristas e pesquisaram, em textos escritos, a maneira como os próprios especialistas definem e esclarecem os conceitos de seu dominio. Entre esses pesquisadores, devem ser mencionados Hearst (1992), Meyer (1996) e Séguella (1999) o quais, a partir de corpora, procuraram identificar os padrões léxico-sintáticos que marcam as relações conceituais e semânticas entre os termos.

Relevante também é o trabalho de Rebeyrolles (1996; 2000a; 2000b) que ampliou a noção usual de marcador, incluindo, além dos elementos lexicais, elementos sintáticos e elementos não-lingüísticos, como sinais tipográficos e elementos de formatação. Além disso, a autora, semelhantemente a Pearson (1998), destacou novos marcadores, derivados da concepção da definição como um ato de fala. Ambas as pesquisadoras enfatizaram o papel dos marcadores discursivos em textos de ciência e tecnologia. Igualmente, Bach Martorell (2001a; 2001b) estudou de modo especial os conetivos reformulativos nos textos de especialidade, assim como Penagos (1999), que investigou as operações metalingüísticas explícitas em textos científicos. Também Candel (2000) não se limitou às definições e pesquisou marcadores de elementos da definição e padrões metalingüísticos. Essas pesquisas lingüísticas têm repercutido sobremaneira no desenvolvimento da Terminologia sob o ponto de vista teórico e também no avanço da Terminografia e suas aplicações, principalmente no que se refere à coleta de termos assistida por computador.

Em suma, aquilo que ora investigamos não é novidade; já foi comprovado devidamente em diferentes idiomas, tais como inglês, francês, espanhol e catalão, entre outros. Em português, até o presente momento, não encontramos estudos semelhan- 
tes. No entanto, o que nos move não é o ineditismo na pesquisa em língua vernácula, mas antes a necessidade de repertoriar e descrever uma terminologia nova numa época em que as ciências e as técnicas já não se apresentam como blocos monolíticos de conceitos hierarquizados em árvores de dominio estabelecidas de antemão. De fato, hoje, a atomização da pesquisa e da tecnologia faz surgir continuamente novas áreas e subáreas de conhecimento. A constante proliferação de campos especializados se observa, por exemplo, no campo da Biologia, onde se desenvolvem pesquisas em novos campos como genômica, biologia genética, biologia molecular, engenharia genética, bioinformática. Assim subáreas se multiplicam, se encontram, se interligam e se sobrepõem umas às outras. Tais áreas são objeto de textos de especialistas, quer dirigidos a outros especialistas, quer ao público não-iniciado no assunto.

Nesse quadro, o estudo piloto ora apresentado encontrou motivação na necessidade de coletar o léxico utilizado nos textos de gestão ambiental, área nova que se insere nos sistemas de gerenciamento empresarial no domínio da Administração de Empresas. Trata-se de um campo de especialidade emergente, que ainda não dispõe de uma terminologia consolidada e, por isso, o processo de repertoriar seus termos se torna complexo. Além disso, a temática é interdisciplinar, posto que se origina de duas áreas, a ambiental e a administrativa, ambas constituídas de um amálgama de várias ciências e técnicas (humanas, sociais, biológicas e exatas).

Destaca-se ainda a ênfase dada à temática pela mídia e o peso a ela conferido pelos sistemas de marketing. De fato, organizações de todos os tipos estão cada vez mais preocupadas em implementar a gestão ambiental a fim de demonstrar que suas atividades se desenvolvem dentro dos princípios do desenvolvimento sustentável sem danificar o ambiente. Para tanto, os empresários buscam informações especializadas no afã de melhor controlar o impacto negativo que possa ser causado por seus produtos ou serviços. Nesse sentido, lançam mão de publicações que, ao veicular conhecimentos, divulgar técnicas, descrever sistemas, utilizam termos que representam e transmitem conceitos os quais devem ser postos em prática satisfatoriamen- 
te. Portanto, a necessidade de entender tais termos justifica plenamente o trabalho que ora empreendemos o qual, por sua vez, pode ser compreendido como a fase preliminar da elaboração de um glossário de Gestão Ambiental Empresarial.

\section{Objetivo}

Este estudo visa a testar duas hipóteses. A primeira é a de que a ocorrência de termos pode ser indicada por elementos que marcam uma definição ou que, ao menos, sinalizam uma explicação de seu significado. A segunda hipótese é a de que tais marcadores se configuram diferentemente de acordo com a natureza da área especializada, os propósitos da comunicação e o contexto situacional.

\section{Metodologia}

A metodologia aqui adotada procura seguir, em linhas gerais, as etapas propostas por Bowker e Pearson (2002) para a pesquisa de textos de linguagem especializada. Para tanto, compreende-se, como etapa preliminar, a composição do corpus dentro da área selecionada, precedida pelo estabelecimento de critérios para a escolha, preparação dos textos, seleção dos instrumentos e decisão dos procedimentos a serem seguidos. Uma vez constituído o corpus, como segunda etapa, tem-se a análise dos textos e a coleta de dados relevantes, seguida de análise e discussão dos resultados.

\section{Constituição do corpus}

O corpus, constituído de um recorte da Base textual TERMISUL, ${ }^{1}$ compõe-se de dois segmentos. O primeiro, chamado corpus básico (CB), abrange cinco normas ISO da Série 14000

\footnotetext{
1 Projeto TERMSUL, Instituto de Letras, UFRGS, http://www.ufrgs.br/ termisul
} 
sobre gestão ambiental, em vigor no Brasil, publicadas sob a responsabilidade da Associação Brasileira de Normas Técnicas (ABNT), como tradução equivalente do original em inglês. São essas as normas 14.001, 14.004, 14.010, 14.011 e 14.012, no total de 26.055 palavras. O segundo segmento, corpus de apoio (CA), compõe-se de capítulos de manuais técnicos usados por aqueles que desejam implementar as normas já citadas. São obras de autores brasileiros e perfazem 106.951 palavras. O corpus totaliza, portanto, 133.006 tokens ou palavras gráficas. ${ }^{2}$

O principal critério da compilação dos textos foi a relevância do documento para o usuário, primordialmente caracterizado como o gestor de empresa. Em primeiro lugar, reunimos os textos da ISO que tratam de gestão ambiental, porque são eles que apresentam as diretrizes necessárias para a obtenção da certificação, sendo esta o testemunho oficial da ISO de que a empresa minimiza o impacto que possa causar ao meio ambiente.

Como se sabe, a ISO, International Organization for Standartization, é uma federação não-governamental e não jurídica de 140 países, entre os quais o Brasil, que estabelece normas para a adequação de bens e serviços a padrões internacionais de excelência. A observância a tais normas não é exigida por nenhuma lei nacional; no entanto, é indispensável para aqueles que desejam receber a certificação. Tal certificação se afigura importante na competição pelo consumidor que, estimulado pela mídia, prefere os produtos que não agridem a natureza. É preciso enfatizar essa circunstância para se entender a natureza do texto da ISO, que malgrado a auto-declaração de não ser normativo, isto é, não ter caráter compulsório, funciona como tal, uma vez que adequar-se a suas exigências é uma condição sine qua non para receber a certificação.

Ao conjunto dessas normas, foram acrescentados textos extraídos de manuais técnicos. Esses manuais são de dois tipos: aqueles que ensinam como implementar as normas e aqueles que colocam as normas sob a ótica da legislação ambiental brasileira.

2 Token ou palavra gráfica é uma seqüência de caracteres gráficos precedida e seguida de um espaço em branco.

TRadTerm, 11, 2005, p. 219-236 
Dessa maneira, os textos do corpus revelam, de um lado, o ponto de vista do especialista (segmento $\mathrm{CB}$ ); de outro lado, segmento $\mathrm{CA}$, os textos revelam o aspecto prático da implementação das normas. Dessa forma, os textos correspondem a uma situação comunicativa bem definida: aquela em que o especialista fala ao não iniciado. No entanto, em um contexto, sobressai a voz da autoridade certificadora, dizendo o que deve ser feito; em outro contexto, ouve-se a voz daquele que ensina. De todo modo, trata-se de um corpus homogêneo quanto ao tema (normas de gestão ambiental), quanto aos interlocutores (especialistas e não-iniciados) e quanto aos propósitos (implementação das normas). O único diferencial dos dois segmentos do corpus é sua função comunicativa: $\mathrm{CB}$ tem caráter prescritivo e $\mathrm{CA}$, caráter didático.

\section{Instrumento de análise}

Os procedimentos de análise de um corpus, na perspectiva da Lingüistica de Corpus, exigem o recurso do computador. Por isso, no propósito de agilizar as buscas e observar os marcadores recorrentes em seu contexto real de uso, utilizamos o aplicativo WordSmith Tools 3.00 (Scott, 1999). Esse aplicativo nos permitiu realizar procedimentos necessários para a coleta de dados: produzir listas de palavras através da ferramenta WordLister, e concordâncias por meio da ferramenta Concordancer.

As listas de palavras nos forneceram, além dos dados estatísticos brutos do corpus básico e do corpus de apoio, as palavras organizadas por freqüência de ocorrência e por ordem alfabética. Através dessas listas, podemos nos familiarizar com as unidades lexicais nos textos sob o ponto de vista lexicográfico, uma vez que foi possível comprovar quais as palavras que são mais usadas e quais aquelas que revelam maior carga semântica da área.

Sob o ponto de vista terminológico, o produto do concordanciador nos trouxe dados relevantes. Na metodologia da Lingüística de Corpus, concordância é uma lista de sentenças em 
em que se apresenta no centro uma mesma palavra, denominada nódulo ou palavra de busca. A sentença pode ser ampliada por um simples clicar de teclas de modo a aumentar a extensão de seu contexto. Assim, torna-se possivel investigar o contexto imediato da palavra pesquisada e reconhecer, como prováveis candidatos a termo, os sintagmas que se repetem.

\section{Análise}

Como procedimento preliminar, foi feita a leitura detalhada das Normas na versão brasileira. Dessa leitura resultaram duas listas de unidades lexicais: uma fechada, composta de 27 termos definidos pela própria norma, e outra aberta, cuja composição recebeu acréscimos à medida que a pesquisa se desenvolveu. A lista aberta recolheu candidatos a termo, isto é, unidades lexicais que, sem descrição terminológica no texto, revelaram algum relacionamento semântico ou pragmático com os integrantes da primeira lista. Esses candidatos a termo serão posteriormente examinados à luz dos princípios que orientam a pesquisa e das informações encontradas no texto. Serão, ainda, submetidos à aprovação dos especialistas da área.

O exame das definições oferecidas pela ISO, como era de se esperar, uma vez que a ISO adota a forma tradicional da definição aristotélica, mostrou um modelo que tende a seguir o rigoroso padrão da Teoria Geral da Terminologia (TGT). São definições por intensão, indicando o gênero próximo e a diferença específica (1); ou definições por extensão, enumerando membros de uma classe dada (2) como se pode observar nos exemplos seguintes, aqui transcritos na formatação original do texto ISO.

desempenho ambiental resultados mensuráveis do sistema de gestão ambiental, relativos ao controle de uma organização sobre seus aspectos ambientais, com base na sua política, seus objetivos e metas ambientais. (1)

organização companhia, corporação, firma, empresa ou instituição, ou parte ou combinação destas, pública ou privada, sociedade anônima, limitada ou com outra forma estatutária, que tem funções e estrutura administrativa

TradTerm, 11, 2005, p. 219-236 
próprias. (2)

Numa pesquisa anteriormente realizada nos textos de Gestão Ambiental no corpus TERMISUL, Birck, (2002) também operou a análise com auxílio do programa WordSmith, investigando o conjunto das cinco normas ISO. A autora arrolou todas as ocorrências do termo "desempenho ambiental". E a análise do contexto dessas ocorrências revelou características do conceito que, uma vez ordenadas e filtradas, complementaram sobremaneira a definição ISO, tornando mais claro o significado do termo. Essa pesquisa ressaltou a relevância de serem procurados mais elementos nos textos das Normas para, de um lado, suplementar as carências das definições oferecidas e, de outro, fornecer elementos para a elaboração de definições de novos candidatos a termo.

Seguindo, pois, esse exemplo, produzimos concordâncias dos 27 termos definidos pela ISO no conjunto de textos do CB. Esse primeiro passo apontou, como principais elementos introdutórios de definição nas Normas ISO examinadas, os hiperônimos genéricos, tais como, processo, resultados, sistema, tratamento, uso, informações, pessoa. Também foi observado o uso de alguns sinônimos, por exemplo: "propósito" significando "objetivo".

Além desses marcadores, também empreendemos a identificação de outros elementos capazes de indicar a ocorrência de elementos definitórios. Assim, encontramos, por exemplo, a unidade fraseológica "Para os efeitos desta Norma", característica das normas jurídicas, conforme já apontado por Bevilacqua (1996); e identificamos recursos tipográficos que funcionam como ponteiros de busca, tais como negritos e aspas, destacando o termo definido e parênteses, indicando sinônimos ou siglas.

Num segundo momento da análise, nos concentramos no corpus de apoio, isto é, no conjunto de textos de manuais técnicos. Um primeiro exame revelou que seus autores tendem a dar explicações que muitas vezes se aproximam de verdadeiras definições; outras vezes reformulam ou explicam as definições dos termos por meio de paráfrases, exemplificações, reiterações ou 
sinônimos, procurando uma formulação mais explícita para o significado. São fragmentos de informação que se distribuem ao longo do texto, e se revelam elementos válidos para o reconhecimento, a compreensão e a respectiva descrição da terminologia usada. Sua presença é assi nalada por marcadores cuja identificação afigura-se como um caminho possivel para a recuperação de elementos definitórios. Tal observação levou-nos a ampliar o escopo das buscas. Recorremos então ao trabalho dos pesquisadores acima mencionados, procurando, em português, equivalentes para os marcadores por eles identificados na língua estrangeira.

\section{Configuração dos marcadores}

A reflexão sobre a análise dos resultados encontrados nos levou a elaborar a configuração dos marcadores. Tal configuração procura articular características léxicas, morfossintáticas, semânticas, pragmáticas e formais. O quadro 1 mostra os marcadores encontrados no $\mathrm{CB}$, enquanto o quadro 2 mostra os marcadores do CA.

\begin{tabular}{|l|l|l|l|}
\hline Hiperônimos genéricos & Fraseologia deôntica & Formatação & Sinais tipográficos \\
\hline $\begin{array}{l}\text { Informações } \\
\text { método } \\
\text { organização }\end{array}$ & Para os efeitos desta & Subtítulo: (DEFINIÇÕES) & Aspas \\
pessoa & Norma & Espaçamento duplo & Parênteses \\
processo & & Negrito & \\
sistema & & Maiúsculas & \\
técnica & & & \\
tratamento & & & \\
resultados & & & \\
\hline
\end{tabular}

Quadro 1: Marcadores de definição e elementos definitórios nas normas ISO

\begin{tabular}{|c|c|c|c|c|c|c|}
\hline $\begin{array}{l}\text { Hiperônimos } \\
\text { Genéricos }\end{array}$ & $\begin{array}{l}\text { Denominações } \\
\text { genéricas }\end{array}$ & $\begin{array}{l}\text { Anunciadores } \\
\text { de paráfrase }\end{array}$ & $\begin{array}{l}\text { Anunciadores } \\
\text { de exemplo }\end{array}$ & $\begin{array}{l}\text { Verbos } \\
\text { denominativos }\end{array}$ & Formatação & $\begin{array}{l}\text { Sinais } \\
\text { tipográficos }\end{array}$ \\
\hline $\begin{array}{l}\text { Método } \\
\text { Processo } \\
\text { Sistema } \\
\text { Técnica } \\
\text { Tratamento }\end{array}$ & $\begin{array}{l}\text { Conceito } \\
\text { Definição } \\
\text { Nome } \\
\text { Termo }\end{array}$ & $\begin{array}{l}\text { Isto é } \\
\text { Quer dizer } \\
\text { Ou seja }\end{array}$ & $\begin{array}{l}\text { Por exemplo } \\
\text { Por ex. }\end{array}$ & $\begin{array}{l}\text { Chamado } \\
\text { Conhecido } \\
\text { Denominado } \\
\text { Definido }\end{array}$ & $\begin{array}{l}\text { Negrito } \\
\text { Maiúsculas }\end{array}$ & $\begin{array}{l}\text { Aspas } \\
\text { Parênteses }\end{array}$ \\
\hline
\end{tabular}

Quadro 2: Marcadores de definição e elementos definitórios na bibliografia de apoio 
sinônimos, procurando uma formulação mais explícita para o significado. São fragmentos de informação que se distribuem ao longo do texto, e se revelam elementos válidos para o reconhecimento, a compreensão e a respectiva descrição da terminologia usada. Sua presença é assi nalada por marcadores cuja identificação afigura-se como um caminho possível para a recuperação de elementos definitórios. Tal observação levou-nos a ampliar o escopo das buscas. Recorremos então ao trabalho dos pesquisadores acima mencionados, procurando, em português, equivalentes para os marcadores por eles identificados na língua estrangeira.

\section{Configuração dos marcadores}

A reflexão sobre a análise dos resultados encontrados nos levou a elaborar a configuração dos marcadores. Tal configuração procura articular características léxicas, morfossintáticas, semânticas, pragmáticas e formais. O quadro 1 mostra os marcadores encontrados no $\mathrm{CB}$, enquanto o quadro 2 mostra os marcadores do CA.

\begin{tabular}{|l|l|l|l|}
\hline Hiperônimos genéricos & Fraseologia deôntica & Formatação & Sinais tipográficos \\
\hline Informações & Para os efeitos desta & Subtítulo: (DEFINIÇõES) & Aspas \\
método & Norma & Espaçamento duplo & Parênteses \\
organização & & Negrito & \\
pessoa & & Maiúsculas & \\
processo & & & \\
sistema & & & \\
técnica & & & \\
tratamento & & & \\
resultados & & \\
\hline
\end{tabular}

Quadro 1: Marcadores de definição e elementos definitórios nas normas ISO

\begin{tabular}{|c|c|c|c|c|c|c|}
\hline $\begin{array}{l}\text { Hiperônimos } \\
\text { Genéricos }\end{array}$ & $\begin{array}{l}\text { Denominações } \\
\text { genéricas }\end{array}$ & $\begin{array}{l}\text { Anunciadores } \\
\text { de paráfrase }\end{array}$ & $\begin{array}{l}\text { Anunciadores } \\
\text { de exemplo }\end{array}$ & $\begin{array}{l}\text { Verbos } \\
\text { denominativos }\end{array}$ & Formatação & $\begin{array}{l}\text { Sinais } \\
\text { tipográficos }\end{array}$ \\
\hline $\begin{array}{l}\text { Método } \\
\text { Processo } \\
\text { Sistema } \\
\text { Técnica } \\
\text { Tratamento }\end{array}$ & $\begin{array}{l}\text { Conceito } \\
\text { Definição } \\
\text { Nome } \\
\text { Termo }\end{array}$ & $\begin{array}{l}\text { Isto é } \\
\text { Quer dizer } \\
\text { Ou seja }\end{array}$ & $\begin{array}{l}\text { Por exemplo } \\
\text { Por ex. }\end{array}$ & $\begin{array}{l}\text { Chamado } \\
\text { Conhecido } \\
\text { Denominado } \\
\text { Definido }\end{array}$ & $\begin{array}{l}\text { Negrito } \\
\text { Maiúsculas }\end{array}$ & $\begin{array}{l}\text { Aspas } \\
\text { Parênteses }\end{array}$ \\
\hline
\end{tabular}

Quadro 2: Marcadores de definição e elementos definitórios na bibliografia de apoio 


\section{Marcadores genéricos}

Os marcadores genéricos podem ser de dois tipos: semânticos e metalingüisticos. Os primeiros indicam relação lexical de hiperonímia. São substantivos cuja função é apontar o gênero próximo no qual a entidade definida se insere. São palavras como "processo", "técnica", "método", "tratamento", "sistema", geralmente usadas nas definições por intensão da terminologia tradicional. Vejam-se, a seguir, alguns exemplos:

melhoria continua processo de aprimoramento do sistema de gestão ambiental, visando atingir melhorias no desempenho ambiental global de acordo com a política ambiental da organização. (ABNT, 1996a, p. 3)

A incineração é um método de disposição de resíduos que se utiliza da decomposição térmica via oxidação, com o objetivo de tornar o resíduo menos volumoso, menos tóxico ou atóxico ou ainda eliminá-lo... (Viterbo Júnior, 1998, p. 67)

Os marcadores genéricos metalingüísticos não adiantam nenhuma noção sobre o significado, apenas descrevem o significante, qualificando-o como termo, definição, conceito ou simplesmente nome. São, na verdade, meras denominações genéricas, tal como se observa no exemplo abaixo:

Há pesquisadores que utilizam o termo acidente natural, enquanto alguns preferem desastre natural. Outros, ainda, diferenciam estes dois termos, considerando que os desastres naturais são acidentes de grandes proporções. A partir da definição de acidente natural, pode-se entender perfeitamente o conceito de risco. Risco é a condição potencial de ocorrência de um acidente. (Cerri, 1999, p.135)

\section{Fraseologia deôntica}

Algumas fraseologias aparecem tipicamente em determinados textos; por exemplo, no texto legislativo em que a expres- 
são "Para os efeitos desta lei" é freqüente. Essa fraseologia circunscreve o enunciado que lhe segue à situação jurídica descrita no texto. E o faz de tal maneira que se lhe pode atribuir um caráter deôntico normativo, uma vez que implica o dever de pautar o significado do texto às exigências legais nele expressas. No texto das normas, a ocorrência de "Para os efeitos desta Norma, aplicam-se as seguintes definições" confirma o aspecto prescritivo desse documento. Por isso no corpus de apoio tal fraseologia não tem razão de ser e, portanto, não aparece.

\section{Verbos denominativos}

Neste grupo se incluem verbos como "chamar", "denominar", "conhecer" os quais se apresentam, na maioria das vezes, na forma do particípio passado:

A cadeia termina em microrganismos - chamados genericamente 'decompositores -, que consomem organismos mortos e outros dejetos orgânicos como fonte de matéria e de energia. (Branco, 1997a, p. 24)

Ainda dentro deste grupo podemos considerar o verbo "definir", embora ele não seja propriamente um verbo denominativo:

demanda química de oxigênio (DQO) - pode ser definida como a quantidade de oxigênio necessária para a oxidação da matéria orgânica presente num efluente através de um agente químico. (Viterbo Júnior, 1998, p. 60)

\section{Conetores reformulativos: anunciadores de paráfrase e exemplos}

Os conetores reformulativos reapresentam o significado através de significantes diferentes, reformulando sua definição, desenvolvendo o conceito apresentado ou o ilustrando através de exemplos. Quando repetem o conteúdo semântico, mas diversificam as estruturas e as formas lexicais, como se perce- 
be no exemplo (3), são anunciadores de paráfrase. Quando introduzem exemplos, como em (4), são os anunciadores de exemplos. Tais conetores são freqüentes em CA, mas não ocorrem em CB:

mas é causa de outro grave problema: o esgotamento dos recursos naturais não-renováveis, isto é, (3) aqueles que, uma vez consumidos, não podem ser novamente repostos, como, por exemplo, (4) o petróleo e os minérios em geral. (Branco, 1997b, p.44)

\section{Marcadores formais}

A leitura do $\mathrm{CB}$ e do $\mathrm{CA}$ revelou que, freqüentemente, aspectos visuais, tais como a disposição gráfica do texto na página, a seleção das fontes, são usados para assinalar a presença de termos e definições. Esses recursos, aqui denominados marcadores formais, constituem dois grupos: o primeiro compreende as rubricas referentes à formatação, e o segundo se compõe de sinais tipográficos.

As definições das normas obedecem a uma disposição gráfica regular: o termo a ser definido aparece em negrito e em letras minúsculas seguido de espaçamento duplo. Não foi possível testar o funcionamento desses recursos de escrita eletrônica por conta de limitações técnicas dos instrumentos de análise. Contudo, pudemos constatar, através do concordanciador, que a colocação de sinais tipográficos, como parênteses e aspas, assinala o posicionamento de termos, indica siglas, introduz sinônimos em ambos os corpora. Vejamos algumas ocorrências pertinentes:

"prestador de serviços" corresponde ao "subcontratado" ou "subfornecedor" da NBR ISO 8402. (ABNT, 1996a, p. 6)

Esses ácidos, misturados à água da chuva formam a chamada "chuva ácida" (ou "neve ácida", ou mesmo "umidade ambiental ácida", com smog) que prejudica as plantas. (Moura, 2000, p. 148) 


\section{Discussão dos resultados}

Os dados levantados revelaram que existem mais diferenças do que semelhanças entre a configuração dos marcadores de elementos definitórios em CB e CA. De fato, em primeiro lugar, CA apresenta maior diversificação de marcadores em contraste com $\mathrm{CB}$, que mostra pequena variedade.

Em CB, observa-se o uso quase exclusivo de hiperônimos genéricos, e a preferência pelos recursos de formatação. Tais recursos, repetidos como verdadeiras rubricas de editoração, configuram um padrão característico do texto da norma ISO, que muito se aproxima ao aspecto formal da norma jurídica. Deve-se destacar, ainda, a ocorrência da fraseologia deôntica, tal como a denominamos neste trabalho Essa fraseologia é também própria dos textos legislativos. Tais detalhes antes que visarem ao conhecimento da informação veiculada, parecem tender a modalizar a forma como a informação deve ser entendida, isto é, uma ordem a ser cumprida.

CA é rico em marcadores de elementos definitórios. Usa também hiperônimos genéricos, ainda que em menor escala em relação a $\mathrm{CB}$, o qual prefere as denominações genéricas e os verbos denominativos. CA recorre freqüentemente aos conetores reformulativos, como também aos recursos tipográficos, não de maneira uniforme e regular como acontece em $\mathrm{CB}$, mas nota-se que sempre aparece quando o autor necessita chamar atenção especial do leitor para um termo, uma definição, um esclarecimento ou um sinônimo. O único marcador usado em CB que não aparece em CA é a fraseologia deôntica, o que se explica facilmente pelo caráter didático de um e prescritivo do outro.

Os marcadores mais freqüentes em CA são as denominações genéricas: os substantivos "termo" e "nome"; o particípio passado dos verbos denominativos "chamar" e "denominar"; os conetores reformulativos, "ou seja" e "por exemplo". Como mencionamos acima, esses marcadores não ocorrem em CB. No entanto, quer em $\mathrm{CB}$, quer em $\mathrm{CA}$ os recursos tipográficos das aspas e parênteses são muito comuns. 


\section{Conclusão}

Como primeira conclusão deste estudo exploratório de caráter piloto, empreendido em dois segmentos do Corpus TERMISUL, área ambiental, subárea Gestão Ambiental, podemos dizer que a hipótese de que a ocorrência de termos pode ser indicada por elementos que marcam uma definição é verdadeira. De fato, apesar das limitações da pesquisa, a análise revelou a presença de marcadores que apontam tanto para candidatos a termo, como para fragmentos de informação relevante. Esses fragmentos de informação são capazes de esclarecer o significado de unidades léxicas especializadas nos textos e são conseqüentemente instrumentais para a seleção de candidatos a termo e a elaboração de definições.

A segunda hipótese segundo a qual os marcadores se configuram diferentemente de acordo com a natureza da área especializada, os propósitos da comunicação e o contexto situacional, isso, se não chegou a ser totalmente comprovado, ao menos foi encaminhado para uma pesquisa posterior. Já podemos afirmar, no entanto, que as diferenças encontradas na configuração dos dois segmentos do corpus são devidas ao único diferencial entre os dois: o caráter normativo de um e didático do outro. Isso nos leva a crer que o propósito dos interlocutores (destinador e destinatário) no processo da comunicação é um fator a ser considerado na configuração dos marcadores.

Cabe ressaltar que esta pesquisa é de natureza qualitativa e, portanto, não lança mão de dados quantitativos os quais também poderiam contribuir para a validação dos resultados. Reconhecemos as limitações de uma investigação num corpus de extensão tão reduzida, mas acreditamos que esse conjunto pode ser o primeiro passo para a compilação de uma amostragem maior do registro característico da área. Nossa iniciativa é, pois, o ponto de partida para uma investigação mais refinada da terminologia na Gestão Ambiental Empresarial. 
Referências bibliográficas

BACH MARTORELL, C. (2001a) La reformulació en els textos d'especialitat, un mecanisme per a la divulgació de la ciència. In: BRUMME, J. La historia de los lenguajes iberománicos de especialidad: la divulgación de la ciencia. Barcelona: IULA. p.245-257.

. (2001b) Els connectors reformulatius catalans: analisi $i$ proposta d'apliicació lexicográfica. Disponível em: <http//tdeat.cesca.es/ tesis_upf/available/tdx-0311102-163528/tcbm1de2.pdf.> Acesso em: 03 jan. 2003.

BEVILACQUA, C. R. (1996) A fraseologia jurídico-ambiental.131f. Dissertação (Mestrado em Letras: Estudos da Linguagem) - Instituto de Letras, Universidade Federal do Rio Grande do Sul, Porto Alegre.

BIBER, D. et al. (2000) Corpus linguistics: investigating language structure and use. Cambridge: Cambridge University Press. 300 p.

BIRCK, C. C. V. (2002) Do contexto de ocorrência de termos à definição terminológica. In: SALÃO [DE INICIAÇÃO CIENTÍFICA], 14. FEIRA [DE INICIÇÃO CIENTÍFICA], 11, 2002, Porto Alegre. Livro de resumos. Porto Alegre. p. 931. Resumo 121.

BOWKER, L.; PEARSON, J. (2002) Working with specialized language: a practical guide to using corpora. London: Routledge. 242 p.

CABRÉ, M.T. (1999) La terminología: representación y comunicación: elementos para una teoría de base comunicativa e otros artículos. Barcelona: IULA. 369 p.

CANDEL, D. (2000) La définition chez les scientifiques. Terminologies Nouvelles. n. 21, p. 53-57.

FINATTO, M. J. B. (2001) Definição terminológica: fundamentos teórico-metodológicos para sua descrição e explicação.395f.Tese (Doutorado em Estudos da Linguagem) - Instituto de Letras, Universidade Federal do Rio Grande do Sul, Porto Alegre.

HATHOUT, N. (1996) Pour la construction d'une base de connaissances lexicologiques à partir du trésor de la langue française: les marqueurs superficiels dans les définitions spécialisés. Cahiers de Lexicologie, v. 68, n. 1, p. $137-173$.

HEARST, M. (1992) Automatic acquisition of hyponyms from large text corpora. Proceedings of the $14^{\text {th }}$ International Conference on Computational linguistics (Coling92) Nantes, France, p. 539-545, Jul. Disponivel em: <http://www.sims.berkeley.edu/ hearst/papers / coling2.pdf $>$ Acesso em: 10 abr. 2003. 
PEARSON, J. (1998) Terms in context. Amsterdam: John Benjamins. $242 \mathrm{p}$.

. (1999) Comment accéder aux éléments définitoires dans les textes spécialisés? Terminologies Nouvelles, Nantes, France, n. 19, p. 2128, juin. Disponivel em: <http://www.cfwb.be/franca/termin/ charger/rint 19.pdf> Acesso em: 24 out. 2002.

PENAGOS, C.R. (1999) Operaciones metalingüísticas explicitas en textos especializados. 151f. Traball de recerca dirigit per Mercê Lorente (Doctorat en Lingüístisca Aplicada) - IULA, Universitat Pompeu Fabra, Barcelona.

REBEYROLE, J. (1996) Définition et textes spécialisés: vers une modélisation. Actes de 3 èmes Rencontres de l'Atelier de Doctorants de l'Université de Paris, Paris, n. 7. p. 9-11.

. (2000a) Utilisation de contextes définitoires pour l'acquisition de connaissances à partir de textes. Actes Journées Francophones d'Ingénierie des Connaissances, IC'2000, Toulouse. p. 105-114, maio. Disponivel em: <www.univ-tlse2.fr/erss/textes/pagesperson/ rebeyrol/> Acesso em: 19 mar. 2003.

. (2000b) Forme et fonction de la définition en discours. Thèse de Doctorat Nouveau Régime, Université Toulouse-Le Mirail. Disponível em: <www.univ-tlse2.fr/erss/textes/pagespersos/rebeyrol> Acesso em: 10 mar. 2002.

SCOTT, M. (1999) WordSmith Tool, versão 3.00.00.Oxford: OUP SÉGUELLA, P. (1999) Adaptation semi-automatique dune base de marqueurs de relations sémantiques sur des corpus spécialisés. Terminologies Nouvelles, Nantes, France, n. 19. p. 52-60.

TEMMERMAN, R. (2001) Sociocognitive terminology theory. IN: SIMPOSIO INTERNACIONAL DE VERANO DE TERMINOLOGÍA, 2, 1999, Barcelona. Terminología y cognición.Barcelona: IULA. p. 75-92.

\section{Referências bibliográficas do Corpus}

\section{Corpus Básico}

ASSOCIAÇÃO BRASILEIRA DE NORMAS TÉCNICAS (1996a) NBR ISO 14001 - Sistema de Gestão Ambiental - Especificação e diretrizes para uso. Rio de Janeiro. 14p.

TraDTERM, 11, 2005, p. 219-236 
. (1996b) NBR ISO 14004 - Sistema de Gestão Ambiental - Diretrizes gerais sobre princípios, sistemas e técnicas de apoio. Rio de Janeiro. $32 \mathrm{p}$.

. (1996c) NBR ISO 14010 - Diretrizes para Auditoria Ambiental Princípios Gerais. Rio de Janeiro. 5 p.

. (1996d) NBR ISO 14011 - Diretrizes para Auditoria Ambiental Procedimentos de Auditoria - Auditoria de Sistemas de Gestão Ambiental. Rio de Janeiro. $7 \mathrm{p}$.

. (1996e) NBR ISO 14012 - Diretrizes para Auditoria Ambiental Critérios de Qualificação para Auditores Ambientais. Rio de Janeiro. $6 \mathrm{p}$.

\section{Corpus de Apoio}

BRANCO, S. M. (1997a) Os impactos ambientais. In: O meio ambiente em debate.São Paulo: Moderna. p. 20-27. cap. 3.

BRANCO, S. M. (1997b) O impacto causado pelas indústrias. In: .São Paulo: Moderna. p. 39-44. cap. 6.

CAJAZEIRA, J. E. R. (1997). Sistemas de gerenciamento ambiental. In: . ISO 14001: manual de implantação. Rio de Janeiro: Qualitymark. p. 3-72.

CERRI, L. E. S. (1999) Riscos geológicos urbanos. In: CAMPOS, H.; CHASSOT, A. (Org.) Ciências da terra e meio ambiente: diálogos para (inter)ações no planeta. São Leopoldo: UNISINOS. p. 133-146.

MOURA, L. A. A. de (2000). Porque uma empresa deve melhorar seu desempenho ambiental. In:___. Qualidade e gestão ambiental: sugestões para implantação das Normas ISO 14000 nas empresas. 2. ed. São Paulo: Juarez de Oliveira. p. 44-190.

VITERBO JUNIOR, Ê. (1998). Meio ambiente e sua proteção - fundamentos. In: . Sistema integrado de gestão ambiental. São Paulo: Aquariana, 1998. p. 48-133. 